\title{
LA COMPETENCIA LECTO-LITERARIA PARA EL DESARROLLO DEL PENSAMIENTO CRÍTICO. ESTÉTICA Y ÉTICA EN LA LITERATURA INFANTIL Y JUVENIL Sara Terol Bertomeu Universitat d'Alacant
}

\section{ESTÉTICA Y ÉTICA}

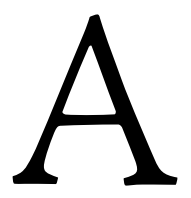
lo largo de la historia, ha habido discrepancias en la unión de las esferas sociales. No obstante, los límites fronterizos entre unas y otras quedan difuminados en la realidad humana. La lectura literaria entraña un encuentro entre la experiencia del lector y el texto, un encuentro con otra persona que vive en un determinado momento con una determinada moral. En el silencio de la lectura, el lector decide dialogar con el otro, escuchar sus opiniones, sus costumbres y sus elecciones. "Tra il lettore e lo scrittore, si producono lo sguardo, la coscienza, il faccia a faccia di una vera e propia relazione etica» (RAIMONDI: 2007, 13-14).

La literatura es una forma de expresión artística y, si queda relegado su valor estético, pierde el sentido de su existencia. Pero no hay que olvidar su capacidad para establecer un encuentro con unos personajes, con el otro. El lector se implica en la historia libremente para encontrarse con una moral que no es la suya. Aunque la estética presentaría la columna vertebral de la literatura, dado que es una creación humana se pueden encontrar secundariamente otras dimensiones de la existencia, como es la moral. Aún más, las teorías éticas no alcanzan el mismo grado de implicación moral que produce la literatura. Mientras que en la ética se reflexiona exteriormente acerca de una determinada moral, en el lenguaje literario el lector puede comunicarse con unos valores morales a través de su responsabilidad en la lectura.

Por ende, si bien la literatura no debe caer en el intento de transmitir valores morales, a lo largo de la historia se ha reconocido un valor en la construcción de la experiencia humana. En el contacto con diferentes vidas, personajes y situaciones, permite a los lectores aumentar su horizonte de posibilidades y reflexionar acerca de sus opciones de futuro. La literatura, al igual que la filosofía, reflexiona acerca de cómo se debería 
vivir y lo hace con un discurso y una forma estética únicos. En este juego literario, el docente tendrá que enseñar a apreciar la literatura como fuente de cultura, diversidad, diálogo e interpretación crítica.

\section{LA COMPETENCIA LECTO-LITERARIA}

El docente de Lengua y Literatura debe conseguir que su alumnado adquiera una formación literaria integral. Para ello, se ha de desarrollar la actividad receptora del alumno en relación con los textos y obras literarias, se ha de conseguir que el alumno consiga construir un significado, una interpretación. Todo ello requiere de la formación de ciertas habilidades en el lector. Unos lectores que irán definiéndose como «autónomos, reflexivos y críticos» (MENDOZA: 2004, 39). En la configuración de este lector literario se desarrolla la clave para la adquisición de un pensamiento crítico, capaz de reflexionar sobre su vida y la relación del hombre con su entorno. El resultado de este proceso parte de la configuración de un lector habitual que adquirirá unos conocimientos literarios y unas habilidades lecto-literarias en progreso.

No obstante, para la adquisición de la competencia lecto-literaria requerimos de un lector y una enseñanza diferente basada en la teoría de la recepción. Para ello, realizaremos un giro copernicano en vistas al lector. Cuanto más rico sea su bagaje lecto-literario, su competencia literaria, más lo será también su interpretación personal. ${ }^{1}$ Gracias al intertexto, los lectores nos convertimos en actores activos en el proceso de lectura y en lectores que disfrutan de la recepción estética. El intertexto del lector debe reorientar la didáctica de la literatura hacia el aprendizaje significativo, hacia el diálogo texto-lector, por medio de la postura activa del mismo. De este modo, la base para la formación de lectores literarios críticos, autónomos y reflexivos no es transmitir la historia de la literatura, sino que «el objetivo de la didáctica de la literatura es orientar para la formación para leer y apreciar la literatura» (MENDOZA: 2004, 81) gracias a la teoría de la recepción, a las estrategias de interpretación, al intertexto lector $y$ al disfrute estético dentro y fuera del aula.

\footnotetext{
${ }^{1}$ Por consiguiente, leer incluye el contenido del lector, el contexto cultural, el contexto vivencial, su intertexto, etc. Con su correspondiente intertexto va confirmando las alusiones que le hace el texto $y$, finalmente, lo comprende e interpreta.
} 
La formación, guiada por el docente, de la competencia literaria se orienta a la teoría de la recepción donde se integran los conocimientos literarios con la experiencia del lector y se fomentan las habilidades para obtener una lectura eficaz. En este transcurso, el lector debe ejercer un papel activo para que forme parte del discurso literario, entendiendo los valores estéticos a través de su experiencia lectora.

3. LA LITERATURA INFANTIL Y JUVENIL EN LA FORMACIÓN DE UN LECTOR COMPETENTE Y AUTÓNOMO

En la literatura infantil y juvenil, advertimos el mismo temor por la subordinación de la estética a la ética. De este modo, podemos distinguimos dos posturas principales. Por un lado, el moralismo que «ha contaminado cualquier intento de pensar críticamente, éticamente» (MATA: $2014,107)$ y parece olvidar los valores estéticos de la literatura. Por otro lado, aquella literatura infantil y juvenil que tiene un lenguaje literario, una determinada forma de relatar, y de ahí que sea capaz de despertar en el lector un diálogo interpretativo, emotivo, crítico. Esta última es la literatura con la que contamos, la verdadera literatura: «La primera cualidad que debemos exigir a un libro es que esté bien escrito. Porque las palabras son el material con que los lectores ordenarán su vida interior» (TEIXIDOR: 2000, 13).

Por consiguiente, «la educación literaria y la educación en valores no tienen por qué discordar, siempre que el valor estético prevalezca sobre cualquier otro» (LLORENS: 2015, 61). A partir de esta idea, es necesario reflexionar ante qué son esos valores morales o sociales a los que nos referimos, cómo aparecen y qué relación establecen con el lector.

\subsection{UNA ESTÉTICA CÍVICA BÁSICA}

Las editoriales, los escritores, los lectores, los padres de los pequeños lectores buscan lecturas que inculquen a sus hijos unos determinados valores morales, es decir, intentan hacerlos partícipes de una determinada moral. Una moral, al igual que la literatura, la escritura o la lectura, depende de un grupo concreto que existe en un espacio y tiempo determinados. 
Una determinada moral, es decir, un sistema de orientaciones para el comportamiento que incluye definiciones de roles sociales, reparto de deberes y de poderes, expectativas mutuas de trato e interacción, y valoraciones sobre determinadas conductas de uno mismo y de los demás miembros del grupo (MARTÍNEZ: 2005, 7).

Cuando se educa, siempre conforme a una moral, se construye una persona con unos determinados comportamientos, normas y valores necesarios para la convivencia, la protección y la adaptación en un grupo social. No obstante, el grupo, a su vez, debe convivir en una sociedad formada por otros grupos con determinadas éticas diferentes.

La coexistencia entre diferentes morales o éticas comprensivas solo será posible con una moral mundial intercultural, es decir, «un conjunto de principios generales que se perciben como aceptables desde diferentes morales locales, y que no implican la desaparición de estas últimas» (MARTíneZ: 2005, 8). Partiendo del pluralismo axiológico, la sociedad comprende diferentes éticas de cada grupo bajo la convivencia de una ética cívica básica. Por consiguiente, a pesar de la diferencia, hay una base moral compartida y sería: la libertad responsable, la igualdad, la solidaridad, el respeto activo y la actitud de diálogo. Valores reflejados en la Declaración Universal de los Derechos Humanos.

Así, la sociedad comprenderá diferentes éticas de cada grupo, o éticas comprensivas, bajo la convivencia de una ética cívica básica. Por consiguiente, a pesar de la diferencia, hay ciertos principios morales que compartimos. El respeto de esa ética cívica básica, ese conjunto de normas, valores y principios que comparten todas las éticas comprensivas, es la que debería servir para juzgar si una determinada opinión, moral o discurso literario es «humanizador» o no lo es. Por ejemplo, decimos que una teoría ética que defiende la moral nazi podría calificarse como inmoral, deshumanizador. Esta determinada ética no podría universalizarse.

En relación a la literatura, en el caso de que elijamos un libro atendiendo al tema que trata, como si por leerlo fuera a transmitir al lector un determinado valor, como si estuviéramos adquiriendo una «vitamina moral», nuestros esfuerzos serán fútiles. La literatura no es una teoría ética, no está hecha para difundir una determinada moral, sino que es un puente ante unas nuevas formas de representación del mundo. Cada per- 
sonaje, cada historia, cada actuación representa una de las miles de formas de vivir en sociedad e intuye a un personaje o a un escritor con una posición moral singular. Un lector activo decide reconocer una determinada forma de vida distinta a la suya. La lectura es testimonio de la posibilidad de un diálogo dentro de la pluralidad humana.

El lector se encauza en un camino de posibilidades donde puede vivir diferentes experiencias morales. La literatura, como el arte en general, ha «evolucionado como una forma de simulación de la realidad, lo que significa poder ensayar los acontecimientos sin incurrir en los gastos de energía o los riesgos de un ensayo real» (MATA: 2014, 111). De este modo, podemos participar emocionalmente en experiencias éticas diversas, con personajes con moralidad variada, etc., incluso ponernos en la piel de personajes que se encuentran en sociedades con un monismo o un politeísmo axiológico.

Se abre un abanico de posibilidades que amplían la experiencia estética y moral. Incluso una historia o un personaje literario nos posiciona «en una postura moral que favorece a la percepción y que nos muestra lo que hubiera supuesto adoptar esa postura en la vida» (NUSSBAUM: 2005, 299). Más aún, una historia o un personaje literario nos permiten examinar nuestras propias vidas con mayor objetividad: «Una novela, precisamente porque no es nuestra vida, nos sitúa en una postura moral que favorece a la percepción y que nos muestra lo que hubiera supuesto adoptar esa postura en la vida» $(2005,299)$. Un lector competente sabrá beneficiarse de la relación entre moral y estética, él elige establecer un diálogo. «La índole de esas compañías y, sobre todo, lo que el lector está dispuesto a dar y recibir, determinará el camino y el desenlace» (MATA: 2014, 110).

\subsection{EL COMPROMISO CON EL OTRO}

Depende del compromiso del lector que se produzca la lectura ética. La literatura «nos habla sobre nosotros, sobre nuestras vidas, elecciones y emociones, sobre nuestra existencia social y sobre la totalidad de nuestras relaciones» (NUSSBAUM: 2005, 315) y el lector decide cuánto escuchar y cómo responder. «Gracias a las características de su lenguaje, la literatura puede expresar cuestiones y dilemas éticos con una profun- 
didad y una emoción de las que carece a menudo la prosa filosófica convencional» (MATA: 2014, 111). La lectura literaria permite el intercambio entre las experiencias de lo narrado y las experiencias del lector. Aunque es el lector el que decide darle vida a cada personaje de la historia. Desde el momento en que el lector apuesta por mantener un papel activo en la lectura, participa de los detalles de la historia.

El término de imaginación narrativa, usado por Nussbaum, se refiere a esa capacidad de ampliar nuestra experiencia al sentirnos dispuestos a participar de una vida que no es la nuestra, a conocer una historia o a una persona y estar dispuestos a compartir sus experiencias, sus emociones o sus fracasos como propios. Esa disponibilidad a entender el mundo que está más allá de nuestra experiencia, a no desentenderse de las vicisitudes humanas y de las grandes cuestiones sociales, es uno de los fundamentos de la ética. Y también de la literatura. La imaginación narrativa encuentra su fundamento en la empatía, permite compartir el estado emotivo del otro, así facilita el diálogo entre lector y texto literario, entre ética y estética, entre realidad y ficción. No solo profundiza en cómo debemos vivir; también nos aporta, desde la tranquilidad de nuestro «sillón de terciopelo verde» (CORTÁZAR: 2010, 8) un enjambre de experiencias y emociones.

En el caso de la literatura infantil y juvenil, estamos hablando de una fuente de experiencias que sirven, al igual que la literatura para adultos, para abrir un abanico de posibilidades en su vida. El lector de literatura infantil y juvenil está aprendiendo a dialogar con el otro, a emocionarse con su relato. A través del estilo literario, se introducirá en la expresión de la diversidad de la compleja vida humana y entenderá algunas de las cuestiones existenciales:

La literatura infantil, como la literatura de adultos, permite imaginar posibilidades, ir al encuentro de mundos desconocidos, conocer nuevas formas de pensar y actuar, simular lo que se quiere decir. Y eso, para los niños que están aprendiendo a vivir, supone una experiencia de carácter ético (MATA: 2014, 112). 


\subsection{LA INTERPRETACIÓN, EL PASO HACIA LA AUTONOMÍA CRÍTICA DEL LECTOR}

Al final del proceso lector, sentimos especial interés en la fase de interpretación, pues esta última fase es primordial para el análisis de la competencia lecto-literaria y el pensamiento crítico. Cuando llegamos a la fase de interpretación, el lector ya ha tenido que llevar a cabo múltiples actividades que tienen un resultado único para cada individuo. El intertexto lector determina la comprensión, pero también la interpretación. La lectura permite interpretar desde el momento en que estamos hablando de un texto literario pues no tiene una voluntad de transmitir explícitamente todo su contenido, significado, ideología, belleza, etc. La forma en la que es creada favorece la participación y rehúsa la mera aceptación.

Es un uso específico del lenguaje (metáforas, referencias, sutilezas, simbolismos, ambigüedades, figuras...) lo que le otorga la cualidad literaria. La polisemia permite la interpretación, lo explícito solo admite la aceptación. Los «espacios vacíos» del texto son los que el lector ocupa con su experiencia y su personalidad. Lo «no formulado» en el texto hace posible que el lector se formule a sí mismo y, por consiguiente, dé sentido personal al texto (MATA: 2014, 115).

La esencia misma del lector activo es la interpretación. Para interpretar, antes hay que recoger información, comprenderla, aprenderla. A partir de «la apreciación subjetiva, la valoración (personales y cultural) y la amplitud o limitación de saberes textuales y metaliterarios» (MENDOZA: 2004, 167), la persona que lee consigue desarrollar un pensamiento autónomo que le permite aprehender $y$, por consiguiente, interpretar aquello que ha adquirido junto a sus conocimientos. Este proceso es fundamental para conseguir progresivamente una independencia reflexiva.

El pensamiento crítico se caracteriza por comprender una serie de conocimientos que transforma en saberes para poder hacerlos propios, por la aprehensión. A lo largo de historia, la aprehensión implica ir más allá de la comprensión, introduciendo una opinión argumentada y responsable al mensaje del texto, al otro. La interpretación es «una síntesis valorativa de su particular recepción comprensiva y de toda la interacción desarrollada entre las aportaciones del texto y del lector» (MENDOZA: 
2004, 167). De este modo, la interpretación no implica una escisión del texto, hay una responsabilidad de no perder al otro por parte del lector. Hay un equilibro entre la comprensión del otro y la diferencia, «l'estetica dell'interprete o dell'esecutore deve convertirsi in un'etica», ya que el lector «è responsabile del suo divenire e del suo rinnovarsi, egli deve insieme conservare quel senso nella sua integrità di soggetto, nella sua differenza» (RAIMONDI: 2007, 19).

La reflexión que surge de la interpretación permite ir más allá de los impulsos y los instintos, hacia una concienciación responsable sobre la conducta, los principios morales y sociales, los valores universales, la convivencia, etc. «La autonomía moral sería la característica humana por antonomasia [...]. Por esa capacidad para ser autónomos se elevan los seres humanos al rango de seres con dignidad, más allá de todo lo que tiene precio» (MARTÍNEZ: 2005, 32).

La teoría literaria de la recepción aboga por ese lector que no es un mero receptor, que es autónomo y reflexiona, que valora e interpreta solo después de haber comprendido. Si la autonomía moral es la característica propia de las personas, el pensamiento crítico es su origen. Los hombres y las mujeres no podemos tener una vida plena sin libertad. Una libertad conlleva responsabilidad, formación, reflexión. «L'homme est condamné a être libre», decía Sartre en L'Etre et le Neant, lo que implica una continua responsabilidad. Pero elección y responsabilidad nos hacen diferentes a cada uno de nosotros, nos ayudan a «pensar frente a la barbarie» (ZAMORA: 2010, 245).

Las personas tenemos un impulso de superación que permite la autocrítica, la reflexión, la argumentación, el desarrollo intelectual, moral y estético, el bienestar individual, etc. Al mismo tiempo, somos seres sociales y eso implica una responsabilidad para los demás, es decir, conlleva la configuración de la ética cívica básica que nos permite convivir en paz y beneficiarnos de esa convivencia. La competencia literaria permite desarrollar el pensamiento crítico a través del proceso de lectura, sobre todo en la interpretación como fundamento de la autonomía personal, la reflexión, la valoración fundamentada. Y, al mismo tiempo, implica que las personas seamos conscientes de la alteridad humana, de la responsabilidad que tenemos en la convivencia. La imaginación narrativa de la lectura 
implica la empatía, la aceptación y la apreciación de una concepción de vida única y diferente a la tuya, y, como escribe Ezio Raimondi, la lectura refiere a un lector autónomo con la responsabilidad de no perder al otro.

Por consiguiente, la lectura desarrolla tanto la dimensión personal del individuo como la social. En el proceso de lectura, se pone en funcionamiento unos mecanismos cognitivos y emocionales, una responsabilidad y una libertad. La interpretación, como elemento de la competencia lecto-literaria y de la educación literaria, juega un papel muy importante para el desarrollo de un pensamiento autónomo y crítico. La necesidad de formar la competencia lecto-literaria, de llegar hasta la última fase del proceso de lectura, de desarrollar un pensamiento crítico, replantea el horizonte didáctico de la literatura.

\subsection{El PAPEL DEL DOCENTE EN LA FORMACIÓN DE UN LECTOR COMPETENTE Y CRÍTICO}

La educación no puede basarse solo en la formación académica, ni puede adoctrinar según una determinada ética comprensiva. La docencia, igual que las demás profesiones, debe ejercerse con imparcialidad conforme a los valores básicos de la ética cívica básica, aunque puedan expresarse las opiniones subjetivas. No solo tendrá que ser imparcial respecto a los valores subjetivos de cada moral, sino que

si queremos que la vida social esté basada en el respeto a los valores de libertad responsable, igualdad, solidaridad, tolerancia activa y actitud de diálogo, las profesiones tendrían que asumir el reto de incluir estos valores en sus respectivos códigos éticos y promoverlos a través de las actividades profesionales mismas (MARTÍNEZ: 2005, 63).

En el caso de los docentes, esta idea es más significativa, puesto que tratan con individuos que configurarán el futuro de la sociedad y que, dado su presente desarrollo, pueden ser fácilmente influenciables. El docente, al desarrollar el pensamiento crítico, da la herramienta a su alumnado para que respete y crea en los valores morales compartidos, rechace los antivalores ${ }^{2}$ y elija con autonomía sus valores diferenciales, para que

\footnotetext{
${ }^{2}$ Aquellos que perjudican a la sociedad, como la violencia.
} 
construyan su vida personal y su responsabilidad hacia el grupo. De esta manera, evitará adoctrinar a su alumnado en una determinada ética comprensiva. El objetivo de la educación se plantea en relación a:

Por una parte, en mostrar honestamente que vivimos en un mundo plural, en el que hay diversas concepciones éticas comprensivas que rivalizan por ganar adeptos entre la población; $y$, por otra parte, la actitud educadora consiste en tratar de desarrollar al máximo las capacidades del alumnado para que llegue a estar en condiciones de elegir con conocimiento de causa entre las diversas opciones posibles (MARTÍNEZ: 2005, 72).

No hay que relacionar el adoctrinamiento con educar en los valores de la ética cívica. En palabras de Martínez, «al tratar de que el alumnado asimile los valores básicos y rechace los antivalores, el educador abre al alumno al pluralismo y al respeto de las diferencias, y desde ahí el propio alumno podrá apreciar la rica diversidad de posiciones rivales y llegar a optar por sí mismo entre ellas» (2005, 72-73). A partir de los valores básicos de la ética cívica, el alumno podrá configurar su propia moral eligiendo aquella ética comprensiva que mejor considere.

\section{CONCLUSIÓN}

La literatura, gracias a la forma de utilizar el lenguaje, permite iniciar un diálogo intelectual y afectivo entre personas diferentes, permitiendo que el lector adquiera experiencias vitales y no solo conocimientos culturales y habilidades en la apreciación lingüística literaria. A partir de la frase de Mandela «education is the most powerful weapon which you can use to change the world», podemos añadir que en el aula de Lengua $y$ Literatura los alumnos pueden disfrutar de una forma de expresión artística que potencie tal cambio, y es la literatura. En definitiva, este trabajo intenta ejemplificar cómo la verdadera literatura y la educación literaria, a través de la formación de la competencia lecto-literaria, puede desarrollar un pensamiento crítico en el alumnado, educándolos como lectores literarios y ciudadanos en esta sociedad. 


\section{Revista de Filologia}

BIBLIOGRAFÍA

CORTÁZAR, Julio (2010): "Continuidad de los parques», en Julio CORTÁZAR, Los relatos, 2. Juegos, Madrid, Alianza Editorial, p. 7 8.

LLORENS, Ramón (2015): «Fábulas, educación literaria y didáctica de los valores: Leo Lionni», Tropelías. Revista de Teoría de la Literatura y Literatura Comparada, núm. 23, p. 61-72.

MARTÍNEZ, Emilio (2005): Ética y fe cristiana en un mundo plural, Madrid, Colección Cruce.

MATA, Juan (2014): «Ética, literatura infantil y formación literaria», Impossibilia, núm. 8, p. 104-121.

MENDOZA, Antonio (2004): La educación literaria. Bases para la formación de la competencia lecto-literaria, Málaga, Aljibe.

NuSSBAUM, Matha (2005): El conocimiento del amor. Ensayos sobre filosofía y literatura, Madrid, A. Machado Libros.

RAIMONDI, Ezio (2007): Un'etica del lettore, Bologna, il Mulino.

TEIXIDOR, Emili (2000): «La literatura juvenil, ¿un género para adolescentes?», Clij. Cuadernos de Literatura Infantil y Juvenil, núm. 133, p. 7-15.

ZAMORA, José (2010): «H. Arendt y Th. W. Adorno: pensar frente a la barbarie», ARBOR. Ciencia, Pensamiento y Cultura, núm. 742, p. 245-263. 